\title{
Feasibility study for interspecialistic collaboration in active research of urothelial neoplasms of professional origin
}

\author{
Roberta Stopponi ${ }^{1}$, Enrico Caraceni ${ }^{2}$, Angelo Marronaro ${ }^{2}$, Andrea Fabiani ${ }^{3}$, Stefania Massacesi ${ }^{1}$, \\ Anna Rita Totò ${ }^{1}$, Roberto Calisti ${ }^{1}$ \\ ${ }^{1}$ Servizio Prevenzione e Sicurezza Ambienti di Lavoro, ASUR Marche AV3, Civitanova Marche, Italy; \\ ${ }^{2}$ Urologia ASUR Marche AV3 - Ospedale Civitanova Marche, Italy; \\ ${ }^{3}$ Urologia ASUR Marche AV3 - Ospedale Macerata, Italy.
}

\begin{abstract}
Summary Introduction: In Italy only a small fraction of cancer is reported to the supervisory body and recognised as professional by the insurance institution. Among the causes of this sub-notification, especially for lowgrade etiologic fractional cancers such as bladder cancers are the lack of knowledge of carcinogenicity in the occupational field and the consequent incomplete medical history collections. Objectives: Diagnosis of occupational bladder neoplasms and activation of systematic surveillance of tumors of professional origin through an "active research" program.

Methods: From July 2010 to July 2017, all patients diagnosed with Bladder Cancer in the departments of Urology of Area Vasta 3 ASUR Marche underwent a first interview and a further anamnestic study in selected cases. When an occupational exposure was recognised, more information for preventive, social security and criminal justice has been acquired. Results: The study highlighted 18 cases of bladder tumors due to occupational exposure to aromatic amines and polycyclic aromatic hydrocarbons, which are the most important risk factor for BC after tobacco smoking.

Conclusions: Our study confirmed that active research is an useful tool both for the activation of epidemiological surveillance and for the regional registration of professional tumors. In addition active research of occupational exposure allow obtaining information that can be used for preventive purposes, for criminal justice and for the initiation of medico-legal actions and improvement of working conditions aimed at guaranteeing workers' rights.
\end{abstract}

KEY WORDS: Bladder Cancer; Occupational Exposure; Epidemiology.

Submitted 2 July 2018; Accepted 19 July 2018

\section{INTRODUCTION}

The contribution of occupational exposures to cancers has been clearly identified. However, occupational exposures in many cancers still remain under-reported. Identification of occupational diseases can result in both a worker's compensation by insurance companies and a reimburse for medical assistance related to the specific condition.

Knowledge of both insurance system and occupational cancer are the main factors that contribute to the request of worker's compensation. Prevalence of occupational cancers vary according to studies design and type of tumor. The first epidemiological study on occupational cancers was conducted in the USA in the 1980s and attributed $4 \%$ of all cancers to occupational exposures ( $8 \%$ for men and $1 \%$ for women) (1); a more recent Finnish epidemiological study (2) considers $8 \%$ of neoplasms (14\% for men and 2\% for women) as of possible professional origin. According to data from AIRTUM 2009 (3), bladder cancer is the $4^{\text {th }}$ most common cancer in Italy, accounting for an estimated 17,000 new cases diagnosed each year. It affects men more frequently than women. Over the years there has been both a reduction in the incidence and mortality of bladder cancer (5-year cancer specific survival of $70 \%$ and $72 \%$, in men and women respectively). Cigarette smoking is the primary risk factor for bladder cancer and several epidemiological studies describe the impact of tobacco smoking on its development. In the developed countries cigarette smoking accounts for 60-66\% of all new cases of bladder cancer. Occupational exposure still remains the second most important risk factor for bladder cancer (4-6).

Correlation between bladder cancer and work environment it is well known since $50^{\text {ths }}$. Occupational exposure accounts for about 5 to $15 \%$ of all cases (7), depending on the criteria adopted and the geographical areas in which the epidemiological studies have been conducted. The most notable occupational agents which act as the main factors for the development of bladder cancer are the aromatic amines, in particular, followed by polycyclic aromatic hydrocarbons (8). This type of occupational exposure occurs mainly in industrial plants which process paints, dyes, metal and petroleum products, as well as in rubber, cosmetic and print industries. Some studies have shown an increased bladder cancer risk among footwear manufacturers.

Despite the clear evidence of correlation between cancer and occupational exposure, the identification of occupational cancer and, consequently, the insurance compensation of workers, are still lacking, in particular in tumors with a low etiologic fraction such as the bladder cancer. This under-reporting is often caused by the confusion between professional exposure and other determinants at the individual level (9). There are many interventions aimed at improving the obligation of notification by doctors. 
A publication by Cochrane (10) says that there is no single intervention that has proven to be effective in improving notifications of professional tumors. On the contrary authors conclude by saying that it is important to create a network that allows a better knowledge of professional tumors. It is also important that this network helps to raise awareness among doctors in the clinical setting and contributes to active case research, to patient information and care facilities.

With the aim of improving notification of professional tumors it is also important their identification by recordlinkage method (11) or the active research of patients affected by professional diseases by questionnaire of occupational history when the patient is admitted to the hospital or after discharge.

Finally, for the sake of completeness, other risk factors involving in the development of bladder cancer are infection by Schistosoma haematobium responsible for a chronic endemic cystitis, frequent use of cyclophosphamide and phenacetine and consumption of water contaminated by arsenic $(12,13)$, that is well known in some italian regions (14).

In the Marche region (OCCAM - OCCupational CAncer Monitoring research 2001-2005), 1629 cases of bladder carcinoma were detected (out of a total of 1,560,785 inhabitants), which is equivalent to 326 cases each year. The professional etiological fraction attributable to the bladder neoplasm is $5-15 \%$, but considering that during the same period (2001-2005) the insurance certification was made only in 13 patients with professional bladder cancer, it is clear that it is sufficient notification of the bladder of the tumor due to occupational exposure. that notification of the bladder tumors due to occupational exposure is not sufficient.

For this reason, considering that in the "Occupational Prevention and Safety Service" - Asur Marche AV3 - of Civitanova Marche, there is the regional registry of tumors with a low etiological fraction (regional resolution of 29 December 2009), we decide to start a research program on the professional origin bladder cancer among patients admitted to two urological departments (Civitanova Marche and Macerata).

\section{Methods}

The Urologists of the Departments involved in the study enrolled urinary bladder cancer patients from August 2010 through a "short" anamnestic questionnaire, preceded by an explanation of the motivation of this "anamnestic supplement". All subjects with bladder neoplasia were included: there were no recruitment restrictions on age, gender, ethnicity or cancer-stage. Subsequently the Occupational doctors selected the subjects who, on the basis of the medical history, according to a preliminary postexposure attribution, could have been professionally exposed to bladder carcinogens.

The Occupational doctors validated

Figure 1. the questionnaires referring to cases of transitional cell urothelial carcinoma accepting/validating only the cases of bladder carcinoma with histological diagnosis of the most typically urothelial or epidermoid form (representing the latter the expression of a carcinogenic process with "chronic irritative" component associated with DNA damage). This selected cases have been subjected to specific occupational anamnesis using a standardised questionnaire called "questionnaire on work, life habits and health" based on the questionnaires used in the the National Register of Nose-Sinus Tumors and the National Registry of Mesotheliomas (ReNaM and ReNaTuns) studies.

Collaterally, was conducted an informative campaign about the occupational bladder neoplasia, about the presence of an "active research of professional neoplasies" and about the possibility for workers and former workers to ask, directly or through a medical request, specific information. The standardised anamnestic questionnaire was directly submitted to the cases reached through this channel.

The diagnoses of occupational disease and the attributions of exposure and cause were based on coherence between the professional history, technological knowledge, epidemiological evidence and, in the absence of other efficient causes, on the etiopathogenetic model.

After the medical history, the Occupational doctor proceeded in the:

- acquisition of company documentation useful for the legal medical investigation

- inspection of the work places if still existing

- assignment of an exposure matrix based on the work history

- expression of a certain, probable or possible judgment on the professionalism or otherwise of the disease

- identification of any responsibility on the part of the company.

\section{RESULTS}

The cases reported by the Departments of Urology and assessed with a brief history were 164 (Figure 1). A further nine cases came to the Service through other channels: five workers, one of whom was advised by his General Practitioner, presented directly to the Medical Department of the PSAL Service, 3 were sent by the Judicial Authority represented by two other PSAL Services of the ASUR Marche and the Judicial Authority

Sources of the cases studied.

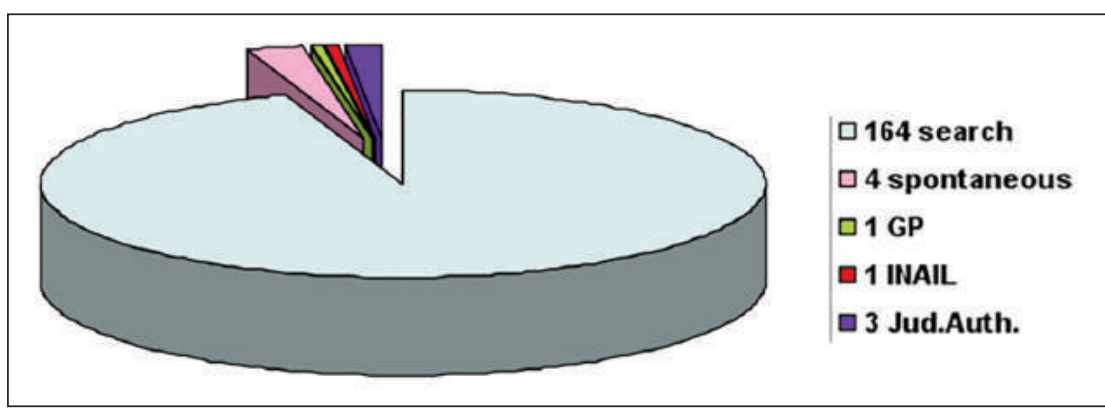


Figure 2.

Work activities.

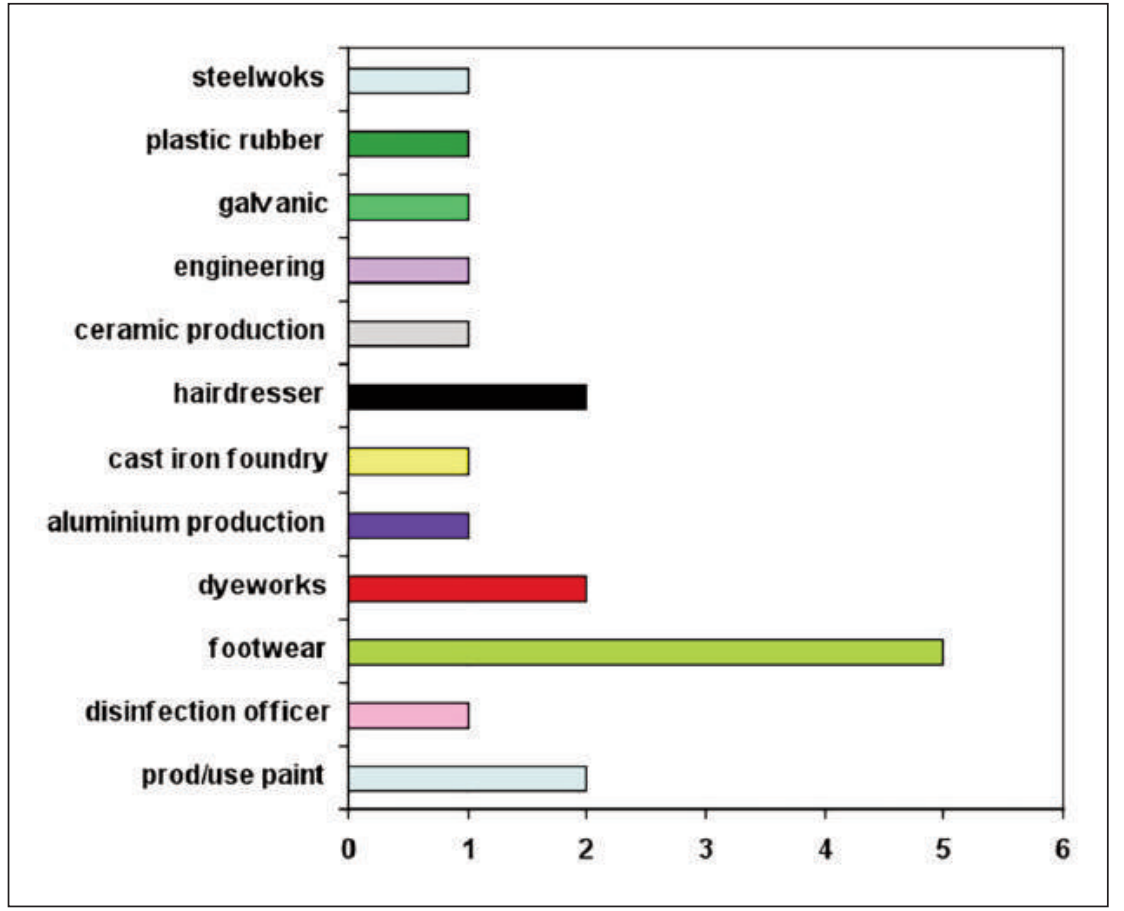

exposures of all the cases reported based on the analysis of the short questionnaires administered by Urologists deciding to contact about a third (50 workers) for a more detailed professional history: of these seven refused further investigations.

After an anamnestic study, an exposure to bladder professional carcinogens was confirmed in more than half of the cases of hospital origin ( $\mathrm{n}=24)$; exposure has been revealed for all nine cases that have reached the Service through the other channels.

From the further anamnestic analysis it was possible to diagnose a professional illness with a certain "attribution of exposure and cause" in 19 cases, all of them male. The insurance process was started for 5 footwear workers, 1 cast-iron founder, 1 aluminum production employee, 2 dyers, 2 paint/varnish production workers, 2 hairdressers, 1 steel worker, 1 metalworker, 1 galvanic worker, 1 plastic rubber pro-

(through a request for investigation) competent for the territory and one through the National Institute for Accident Insurance at Work (INAIL) channel (through reporting) (Figure 1 ).

Overall, 173 cases were evaluated: 27 females and 146 males. In two cases the bladder lesions were benign, while one case showed inflammation.

The average age at the first diagnosis is 71.09 years (for the female) and 70.2 years (for the man): the youngest patient is 30 years old and the oldest is 93 years old). The $21 \%$ of cases are smokers at the time of the questionnaire administration and the $53 \%$ claimed to be an ex-smoker.

The medical staff of SPSAL evaluated the professional duction assistant, 1 disinfection worker, 1 ceramic production worker (Figure 2).

The carcinogenic occupational substances for the bladder are predominantly the aromatic amines (12 cases), the polycyclic aromatic hydrocarbon (4 cases), the tetrachlorethylene (1 case) and the arsenic (1 case) (Figure 3). The average of exposure to this substances is 23 years.

In two workers, other occupational diseases were diagnosed: namely a tumor of the nasal and paranasal sinuses from exposure to leather powder and asbestosis and pleural plaques from exposure to asbestos.

Only two companies are still active in which the exposure of workers to the bladder carcinogens has reasonably occurred.

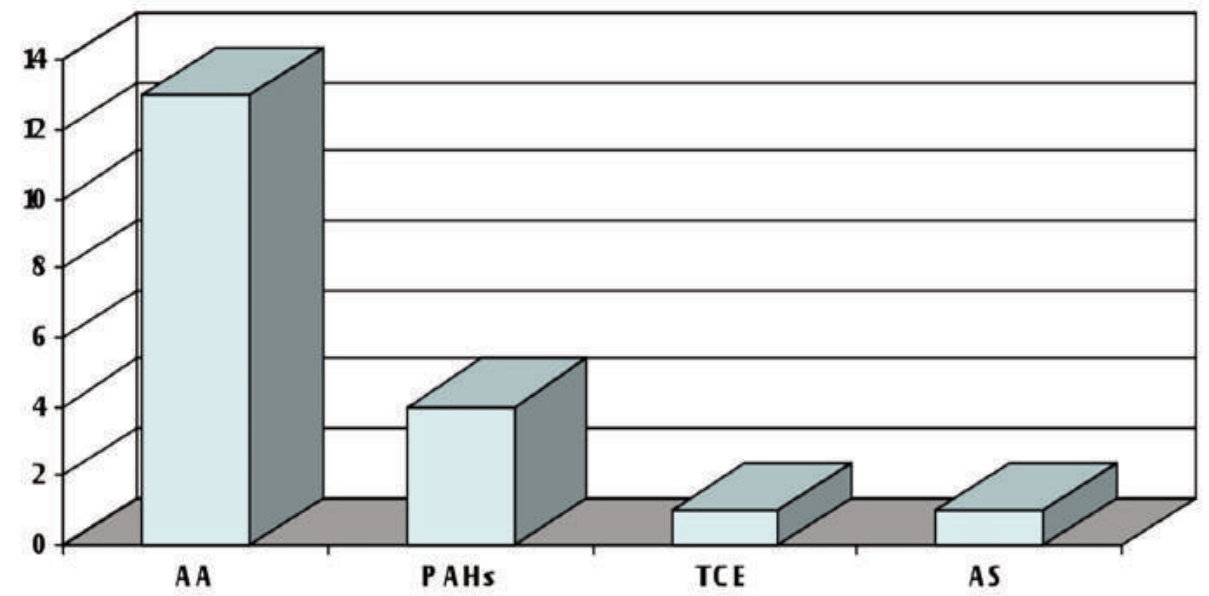

A A
TCE
Figure 3.

Prevalent exposures in cases for which the insurance process has been launched (aromatic amines $A A$, polycyclic aromatic hydrocarbons PAHs, tetrachlorethylene TCE and arsenic AS). 


\section{Discussion}

In our target group of 173 patients affected by bladder cancer, occupational exposure accounts for about $10 \%$ of all cases which is, on average, the worldwide percentage of professional urothelial neoplasms. We expected this result considering the production of local industry.

Tobacco smoking is not relevant for the certification of occupational disease when carcinogenic occupational exposure has been clearly established. Half of the workers for whom a certification request of occupational disease were made to stop smoking (average 36.8 year of smoking) and 20\% were still smoking (30.8 years, on average).

We couldn't find any definitive correlation between occupational exposure and multifocality, grading and histology because our data are insufficient on this purpose.

There are some evidences on the literature that occupational exposure could influence prognosis of bladder cancer so it is advisable to further analyse this aspect with a larger amount of data (15). Otherwise, the correlation between occupational exposure and prognosis does not influence certification of professional disease and workers' compensation.

Only in one patient after the diagnosis of bladder cancer the medical procedure for the certification of professional disease had been started. Therefore we made a request for certification of a professional disease in every patient where occupational exposure was identified except for a patient that needed a further investigation from territorial competent service.

Nowadays, this study confirms that the most important carcinogenic occupational factors for urothelial neoplasm are aromatic amines and polycyclic aromatic hydrocarbons.

In particular we found five patients affected by bladder cancer in leather and footwear industries. Processing of leather and footwear are well known to be an important cause of professional bladder cancer due to exposure to aromatic amines in painting processes.

We also confirm association between bladder cancer and industrial plants which process metal, in particular steel and iron foundries.

This association has been found in other studies too but at the moment there is not significant epidemiological evidence in order to certainly establish a higher risk of bladder cancer in this working context.

Industrial plants which involves aluminium production are also represented. In the literature aluminium industries are associated with the main carcinogens present in the processing and represented by the volatile derivatives of tar pitch.

In our study, in addition to cases of bladder cancer in workers of industrial plants which process paint and dye, association between urothelial neoplasms of the bladder and dyes production which involves use of aromatic amines is also represented.

Exposure to arsenic was the reason why we judged bladder cancer as a professional origin in a disinfestation worker. In fact arsenic was used to produce pesticides in the past (16).

We found a case of bladder cancer in a worker in the galvanic sector. In this case bladder neoplasm is not includ- ed in the list of disease to be denounced according to the Italian legislation. Despite this the first certificate of occupational disease was completed because some studies have showed that exposure to tetrachlorethylene is reasonable associated with an increase of risk of bladder cancer (17).

We managed to found two companies still existing in which the exposure of workers to professional bladder carcinogens reasonably existed.

One was not a local factory and is based outside Marche region. For this reason data was sent to the competent territorial office. Instead the other factory is located in the Marche region so we were able to identify and characterise carcinogens in the work environment and proceed with action aimed at remove them. In addition another target was searching for responsibilities of the company.

The assessment of the presence of clusters is underway in a third company (currently not active) in the Marche region and in a company outside the region.

\section{Conclusions}

Active research of professional bladder neoplasms is a valid and simple tool able to identify cases of cancer of professional origin that otherwise would have remained unknown. Active research of professional cancer should be based on the careful clinical history of the patient, the knowledge of production cycles and information on risks obtained from the scientific literature.

In this contest certification of tumors of professional origin is also important to obtain workers' compensation, to activate the systematic epidemiological surveillance of professional bladder neoplasms, to start the regional registration of these diseases, to certificate effects of occupational carcinogens useful for implementing data that can be used for preventive purpose and to evaluate effectiveness of preventive measures adopted to reduce incidence of these neoplasms.

Our experience confirms that it is fundamental to improve knowledge of bladder carcinogenic risks including professional ones and to implement preventive measures linked not only to life habits but to work environment also.

Apart from competent medicals, it is also important to involve other professional figures like family physicians and specialists pointing out the necessity of collecting a detailed medical history and to report diseases that could be of professional origin because of an exposition to occupational carcinogens in the past.

In addition, Occupational Physicians need to pay attention, promote and control to the establishment of registers of people who have been exposed to occupational carcinogens (ex art 248 D.lgs 81/08 smi). In the same time they have to improve professional prevention by monitoring the application of the legislation regarding the safety of work environment (art 224 e 225 del DlgS $81 / 08 \mathrm{smi}$ ). It is also crucial to promote the demise of artificial rubber extended to aromatic oils, by substitution with materials (paraffinic oils and naphthenic oils) without IPA or with a significantly reduced content of the same. 


\section{REFERENCES}

1. Doll R, Peto R. The causes of cancer: quantitative estimates of avoidable risks of cancer in the United States today. J Natl Cancer Inst 1981; 66:1191-1308

2. Nurminen M, Karjalainen A. Epidemiologic estimate of the proportion of fatalities related to occupational factors in Finland. Scand J Work Environ Health. 2001; 27:161-213.

3. AIRTUM, Associazione Italiana Registro Tumori, "I trend dei tumori negli anni duemila", 2009, http://www.registritumori.it/ cms/?q=Rapp2009Indice.

4. Letašiová S, Medve'ová A, Šovcíková A, et al. Bladder cancer, a review of the environmental risk factors. Environ Health 2012; 11(Suppl 1):S11.

5. Burger M, Catto JWF, Dalbagni G, et al. Epidemiology and risk factors of urothelial bladder cancer. Eur Urol. 2013; 63:234-241.

6. Miyazaki J, Nishiyama H. Epidemiology of urothelial carcinoma. Int J Urol. 2017; 24:730-734.

7. Olfert SM, Felknor SA, Delclos GL. An updated review of the literature: risk factors for bladder cancer with focus on occupational exposures. South Med J. 2006; 99:1256-63.

8. Cumberbatch MG, Cox A, Teare D, Catto JW. Contemporary occupational carcinogen exposure and bladder cancer: a systematic review and meta-analysis. JAMA Oncol. 2015; 1:1282-90.

9. Crosignani P, Amendola P, Audisio R, et al. [Confounding and confusion: recognition of causative relation and identification of victims of occupational carcinogens]. G Ital Med Lav Ergon. 2008; 30:3925. (Article in Italian).

10. Curti S, Sauni R, Spreeuwers D, et al. Interventions to increase the reporting of occupational diseases by physicians. Cochrane Database Syst Rev. 2015;(3):CD010305. doi: 10.1002/14651858. CD010305.pub2.

11. www.occam.it

12. Silverman DT, Devesa SS, Moore LE, Rothman N. Bladder cancer In Schottenfeld D, Fraumeni JF Jr (eds) Cancer Epidemiology and Prevention, 3rd ed, New York, NY 2006, Oxford University Press, pp 1101-1127.

13. Nuckols JR, Freeman LE, Lubin JH, et al. Estimating water supply arsenic levels in the New England Bladder Cancer Study. Environ Health Perspect. 2011; 119:1279-85.

14. Di Lorenzo G, Federico P, De Placido S, Buonerba C. Increased risk of bladder cancer in critical areas at high pressure of pollution of the Campania region in Italy: A systematic review". Crit Rev Oncol Hematol. 2015; 96:534-41.

15. Selinski S, Bürger H, Blaszkewicz M, et al. Occupational risk factors for relapse-free survival in bladder cancer patients. J Toxicol Environ Health A. 2016; 79:1136-1143.

16. Boulanger M, Tual S, Lemarchand C, et al. Agricultural exposure and risk of bladder cancer in the AGRIculture and CANcer cohort. Int Arch Occup Environ Health. 2017; 90:169-178.)

17. Vlaanderen J, Straif K, Ruder A, et al. Tetrachloroethylene exposure and bladder cancer risk: a meta-analysis of dry-cleaning-worker studies. Environ Health Perspect. 2014; 122:661-6.

\section{Correspondence}

Stopponi Roberta, MD (Corresponding Author)

Massacesi Stefania, MD

Totò Anna Rita, MD

Calisti Roberto. MD

Servizio Prevenzione e Sicurezza Ambienti di Lavoro, ASUR Marche AV3, Civitanova Marche, Italy

Caraceni Enrico, MD

Marronaro Angelo, MD

ang6marr@yahoo.it

Urologia ASUR Marche AV3 - Ospedale Civitanova Marche (Italy)

Fabiani, MD

Urologia ASUR Marche AV3 - Ospedale Macerata (Italy) 